\title{
Significance of Axial Heat Dispersion for the Description of Heat Transport in Wall-cooled Packed Beds
}

\author{
J. G. Harold Borkink and K. Roel Westerterp*
}

A two-dimensional pseudo-homogeneous model with axial dispersion of heat has been solved numerically with different boundary conditions at the inlet and outlet of the packed bed. The model solutions are fitted to experimental temperature profiles, determined in a wall-cooled packed bed in which a hot gas is cooled down, and best fit values of the effective axial and radial thermal conductivities and the wall heat transfer coefficient are obtained. In the range of Reynolds numbers employed, $\operatorname{Re}_{\mathrm{p}}^{\mathrm{s}}>50$, the axial dispersion of heat is found to be of no significance for the description of heat transport in wall-cooled packed beds without reaction, provided that the inlet boundary conditions are chosen appropriately. If a radially flat inlet temperature profile is assumed, while the actual profile is curved, an apparent improvement in the description of heat transport is observed when axial dispersion is incorporated into the heat balance and high effective axial thermal conductivities are obtained. If a Danckwerts type inlet boundary condition is used, assuming a flat temperature profile immediately in front of the inlet, an apparent improvement is also found on incorporation of axial dispersion of heat. This is caused by the temperature jump at the inlet, compensating for the overestimation of inlet temperature, in the case of cooling. The latter also explains why the inclusion of axial dispersion may eliminate the so-called "length effect", often related to the effective radial thermal conductivity and the wall heat transfer coefficient. It is shown for the outlet boundary condition that deletion of the axial dispersion term from the heat balance at the outlet is a convenient boundary condition for the model being solved numerically.

\section{Introduction}

Axial dispersion of mass and heat in packed beds has been of much interest for many years. Pioneering work in this field was, among others, performed by Wilhelm who was one of the first investigators to show experimentally that the Peclet number for axial dispersion of mass, at fully developed flow, equals two [1]. This agrees with the value predicted theoretically on the assumption of the packed bed acting as a series of $n$ perfect mixers, where $n$ is the number of voids between the particles traversed between the inlet and outlet of the packed bed. Since 1970, axial dispersion of heat gained even more interest, for example, through the work of Young and Finlayson [2]. They showed that inclusion of axial heat dispersion in the modelling of heat transport in a cooled tubular reactor, under reaction conditions, can significantly alter the predicted temperature profiles. They derived a criterion for determining under what conditions can axial heat dispersion be neglected. This criterion is independent of the reactor length, whereas computer calculations, e.g. of Carberry and Wendel [3], Marek and Hlavacek $[4,5]$, who calculated axial temperature and conversion profiles for heterogeneous exothermic reactions in an adiabatic packed bed reactor, indicate that the significance of axial heat dispersion decreases with increas-

* Dr. Ir. J.G.H. Borkink and Prof. Dr. Ir. K. R. Westerterp, Chemical Reaction Engineering Laboratories, Department of Chemical Engineering, Twente University of Technology, PO Box 217, 7500 AE Enschede, The Netherlands. ing bed length. Later, Mears [6] derived a criterion for neglecting the axial dispersion of heat in non-isothermal packed bed reactors, based on the inlet rate data, which does depend on reactor length. Recently, extensive computer calculations showed axial dispersion of heat to be of minor importance for practical conditions, see e.g. [7-9]. These and other seemingly contradictory results lead to confusion about the significance of reactor length combined with axial heat dispersion for the modelling of e.g. cooled tubular reactors.

\subsection{Criteria for Neglecting Axial Dispersion of Heat}

For the description of heat transport without reaction in wall-cooled or heated packed beds, axial heat dispersion is usually neglected. Model calculations for these, so-called cold-flow experiments show the temperature profiles to be relatively insensitive to the value of the effective axial thermal conductivity $\lambda_{\mathrm{e}, \mathrm{a}}[10-12]$. This is also the reason why this parameter is usually determined in adiabatic packed beds, employing either dynamic $[13,14]$ or steady-state experiments $[14,15]$.

$\mathrm{Li}$ and Finlayson [16] present an expression for the error in the effective radial thermal conductivity $\lambda_{\mathrm{e}, \mathrm{r}}$ and the wall heat transfer coefficient $\alpha_{w}$, if these are determined from cold-flow experiments by fitting a pseudo-homogeneous two-dimensional model to experimental temperature pro- 
files and omitting axial dispersion of heat. This expression is: ${ }^{1)}$

$\frac{\Delta \lambda_{\mathrm{e}, \mathrm{r}}}{\lambda_{\mathrm{e}, \mathrm{r}}}=\frac{\Delta \alpha_{\mathrm{w}}}{\alpha_{\mathrm{w}}}=-\frac{24}{\mathrm{Bo}_{\mathrm{h}, \mathrm{r}} \mathrm{Pe}_{\mathrm{h}, \mathrm{a}}} \frac{\mathrm{Bi}_{\mathrm{t}}}{N^{2}\left(3+\mathrm{Bi}_{\mathrm{t}}\right)}+\frac{1}{2 N \Gamma}$

A similar criterion for neglecting axial dispersion of heat in cold-flow experiments has recently been presented by Wijngaarden [17]. This criterion can be written as:

$\Xi=\frac{32}{\mathrm{Bo}_{\mathrm{h}, \mathrm{r}} \mathrm{Pe}_{\mathrm{h}, \mathrm{a}}} \frac{\mathrm{Bi}_{\mathrm{t}}}{N^{2}\left(4+\mathrm{Bi}_{\mathrm{t}}\right)}<\xi$

in which $\xi=0.1$ for a closed-closed system and $\xi=0.4$ for an open-closed system. For $\operatorname{Re}_{\mathrm{p}}^{\mathrm{s}}>50$, the relevant dimensionless numbers become independent of $\operatorname{Re}_{\mathrm{p}}^{\mathrm{s}}$ and the following typical values are obtained:

$\mathrm{Pe}_{\mathrm{h}, \mathrm{a}}=1-2, \mathrm{Bo}_{\mathrm{h}, \mathrm{r}}=4-8$ and $\mathrm{Bi}_{\mathrm{t}}=1-5$.

For a short and narrow tube with $N=5$ and $\Gamma=10$, this yields for Eqs (1) and (2):

$\frac{\Delta \lambda_{\mathrm{e}, \mathrm{r}}}{\lambda_{\mathrm{e}, \mathrm{r}}}=\frac{\Delta \alpha_{\mathrm{w}}}{\alpha_{\mathrm{w}}}=-0.14$ and $\Xi=0.2$,

respectively. Thus, for sufficiently high Reynolds numbers, axial dispersion of heat can usually be neglected for the description of heat transport without reaction in wall-cooled or heated packed beds. But, at lower Reynolds numbers, a small diameter tube and a small number of particles on a diameter, the axial dispersion of heat may become significant.

\subsection{Apparent Length Dependence}

Several workers observed an apparent dependence on length of $\lambda_{e, r}$ and $\alpha_{w}$, as applied in the pseudo-homogeneous twodimensional model, and of $U_{\text {or }}$, as used in the one-dimensional model, often referred to as the "length effect" [16, $18,19]$. It was also found that this length effect can be eliminated by taking axial dispersion of heat into account $[20-22]$.

\subsection{Objective of the Present Investigation}

The significance of axial dispersion of heat for the description of heat transport in a wall-cooled packed bed is studied and, to this end, a pseudo-homogeneous two-dimensional model with axial heat dispersion is solved numerically. The influence of the boundary conditions at the inlet and outlet is elaborated and a possible explanation given for the apparent elimination of the length effect by incorporation of axial dispersion.

1) List of symbols at the end of the paper.

\section{Model Equations and Experimental Set-up}

\subsection{Model Equation}

The system studied is a hot gas, cooled down in a wallcooled packed bed. For describing heat transport in the packed bed, the following assumptions are made:

- the system is at steady state and no reaction is taking place,

- the system is considered to be pseudo-homogeneous,

- there is no free convection of heat,

- there is no radiation,

- the superficial velocity is constant over the radius,

- the wall temperature is constant,

- the physical properties of gas and solid are independent of temperature.

A heat balance for an infinitesimally small ring yields the following dimensionless model equation:

$\frac{\partial \theta}{\partial \omega}-\frac{1}{\mathrm{Pe}_{\mathrm{h}, \mathrm{a}}^{\Theta}} \frac{\partial^{2} \theta}{\partial \omega^{2}}-\frac{1}{\mathrm{Bo}_{\mathrm{h}, \mathrm{r}}^{\Theta}} \frac{1}{\varrho} \frac{\partial}{\partial \varrho}\left(\varrho \frac{\partial \theta}{\partial \varrho}\right)=0$

where $\theta$ is given by $\theta=\left(T_{z, \mathrm{r}}-T_{\mathrm{cl}}\right) /\left(T_{0}-T_{\mathrm{cl}}\right)$ and $T_{0}$ is the temperature measured at a point on the axis of the packed bed, defined as the location where $\omega=0$.

\subsection{Boundary Conditions}

The following boundary conditions are chosen in radial direction:

$\varrho=0$, all $\omega, \frac{\partial \theta}{\partial \varrho}=0$

$\varrho=1$, all $\omega, \quad \frac{\partial \theta}{\partial \varrho}=-\mathrm{Bi}_{\mathrm{t}} \theta$

Several possibilities exist for the boundary conditions in axial direction $[10,23]$. The system can be considered as open to axial dispersion of heat at the inlet and/or outlet, or it is considered to be closed to axial dispersion, yielding the well-known Danckwerts boundary conditions. For open boundary conditions at the inlet and outlet, a radial temperature profile is adopted, which is assumed to be parabolic in shape. Either of the following inlet boundary conditions is considered:

$\omega=0$, all $\varrho, \quad \theta=1-A \varrho^{2}$,

$\omega=0$, all $\varrho, \quad \frac{\partial \theta}{\partial \omega}=-\mathrm{Pe}_{\mathrm{h}, \mathrm{a}}^{\Theta}\left(1-A \varrho^{2}-\theta\right)$.

In addition, the following outlet boundary conditions are also considered: 
$\omega=1, \quad$ all $\varrho, \quad \theta=B-C \varrho^{2}$,

$\omega=\omega_{\text {out }}$, all $\varrho, \frac{\partial \theta}{\partial \omega}=0$,

$\omega=\omega_{\text {out }}, \quad$ all $\varrho, \frac{1}{\mathrm{Pe}_{\mathrm{h}, \mathrm{a}}^{\theta}} \frac{\partial^{2} \theta}{\partial \omega^{2}}=0$

In Eqs (6b) and (6c), $\omega_{\text {out }}$ is an axial position downstream from the outlet of the packed bed, thus $\omega_{\text {out }} \geqslant 1$.

Eqs $(5 a)$ and $(6 a)$ represent the boundary conditions for an open-open system. In the evaluation of experimental data, values of constants $A, B$ and $C$ are obtained by fitting the equations to experimental radial temperature profiles at the locations $\omega=0$ and $\omega=1$. Therefore, the data at $\omega=0$ and $\omega=1$ are not used for model fitting. Eq. (5b) expresses the closed Danckwerts boundary condition at the inlet. The temperature profile immediately before the inlet at $\omega=0$ is assumed to be of parabolic shape and a "temperature jump" at $\omega=0$ is also assumed. For the system considered here, this is not a realistic assumption because the position $\omega=0$ is situated inside the packed bed, so that the temperature profile will be continuous; there is no reason to assume that axial dispersion would not occur in the region where $\omega<0$. However, since Eq. (5b) is often used in the literature, its influence on the effective axial conductivity $\lambda_{\mathrm{e}, \mathrm{a}}$ is studied. Eq. (6b) expresses the closed Danckwerts boundary condition at the outlet. In practice, gas temperature never becomes equal to the coolant temperature and therefore Eq. (6b) is never exactly valid. However, if the axial position at which Eq. (6b) is assumed to be valid is sufficiently distant from the actual bed outlet, i.e. $\omega_{\text {out }} \gg 1$, the error incurred by using Eq. (6b) will be small. Therefore, the value of $\omega_{\text {out }}$ needed to minimize the error is determined for a wide range of $\lambda_{e, a}$ values. The boundary condition given by Eq. (6c) may appear strange. It is obtained by deleting the axial dispersion term from the heat balance given by Eq. (3) at $\omega=\omega_{\text {out }}$. This has no physical basis, but Eq. $(6 \mathrm{c})$ is a convenient boundary condition for a numerical solution of the equations. Eq. (6c) does not mean that there is no axial heat dispersion beyond the plane where $\omega=\omega_{\text {out }}$; it is an open boundary condition and only indicates that the term $\left(1 / \mathrm{Pe}_{\mathrm{h}, \mathrm{a}}^{\Theta}\right)^{2} \theta / \partial \omega^{2}$ is small enough to be neglected in the heat balance.

\subsection{Determination of Best Fit Values for Heat Transfer Coefficients}

Eqs (3) - (6) were solved numerically with an upwind finite differences technique in axial direction, coupled with an interior collocation method in radial direction, see appendix. This numerical procedure proved to be very stable and relatively fast for a wide range of $\mathrm{Bo}_{\mathrm{h}, \mathrm{r}}^{\ominus}, \mathrm{Pe}_{\mathrm{h}, \mathrm{a}}^{\ominus}$ and $\mathrm{Bi}_{\mathrm{t}}$ values. Best fit values for $\lambda_{e, r}, \lambda_{e, a}$ and $\alpha_{w}$ were obtained by adjusting these parameters until a best fit solution of Eqs (3) - (6) to the experimental temperature profiles was found. The objective function minimized is a chi-square target function, calculated according to: $\chi^{2}=\sum_{i=1}^{n}\left(\frac{\theta_{\mathrm{i}}-\theta\left(\varrho, \omega, \lambda_{\mathrm{e}, \mathrm{r}}, \lambda_{\mathrm{e}, \mathrm{a}}, \alpha_{\mathrm{w}}\right)}{\sigma_{\mathrm{i}}}\right)^{2}$.

In Eq. (7), $n$ is the number of temperature measurements, $\theta_{\mathrm{i}}$ denotes the experimental temperature, $\theta\left(\varrho, \omega, \lambda_{\mathrm{e}, \mathrm{r}}, \lambda_{\mathrm{e}, \mathrm{a}}, \alpha_{\mathrm{w}}\right)$ the value predicted by the model and $\sigma_{\mathrm{i}}$ is the standard deviation of the measured temperatures. The chi-square target function is minimized using a Nealder-Mead method in multidimensions with different starting points [24].

\subsection{Experimental Set-up}

The device for measuring radial and axial temperature profiles contains three stainless steel wall-cooled tubes, $1.33 \mathrm{~m}$ long and with inner diameters of $49.9,63.5$ and $99.0 \mathrm{~mm}$. The tubes were filled with packing and cooled with water at about $283 \mathrm{~K}$, flowing through a jacket. Hot air at about $333 \mathrm{~K}$, flowed upwards through the tubes and was cooled at the wall. Under steady-state conditions, the radial temperature profile was measured near the top of the bed, with 7 to $15 \mathrm{~K}$-type thermocouples, $0.5 \mathrm{~mm}$ in diameter, fixed in a rectangular rod of $2 \times 2 \mathrm{~mm}$ mounted radially through the centre of the bed. The rod is made of a poorly conducting material, so that the measured temperatures were not affected by conduction through it. The temperature of the gas at the inlet to the packed bed, coolant temperature at inlet and outlet, pressure upstream of and downstream from the bed and the gas flow rate were also measured. The pressure drop across the bed was always less than 0.1 bar and therefore neglected. A flow sheet of the equipment is shown in Fig. $1 \mathrm{a}$ and a diagram of the tubes in Fig. $1 \mathrm{~b}$.

The bed height in a tube can be increased by lowering the piston in the bottom of the tube and adding extra packing material, maintaining the top surface of the packing at the same level in the tube. By altering the bed height in this way, it is possible to obtain radial temperature profiles at different axial positions or bed lengths. This is shown schematically in Fig. $1 \mathrm{c}$. Also, the tubes are designed in such a way that the bed can be easily repacked by fluidizing the packing for a short time. Care was taken to maintain the bed height, and thus the average bed porosity, the same throughout one whole experimental series. The individual dimensionless radial temperature profiles, obtained from measurements, were averaged to one mean profile for a given bed length. This also produced values of the standard deviation for every radial point. Combination of the average radial temperature profiles, obtained for different bed heights at the same experimental conditions, yields the temperature field for the whole tube.

All experiments reported here were performed with air at atmospheric pressure, for which the following physical properties applied at 1 bar and $313 \mathrm{~K}: \varrho_{g}=1.13 \mathrm{~kg} \mathrm{~m}^{-3}$, $C_{\mathrm{pg}}=1014 \mathrm{~J} \mathrm{~kg}^{-1} \mathrm{~K}^{-1}, \quad \eta_{\mathrm{g}}=19.04 \times 10^{-6} \mathrm{Pas}$ and $\lambda_{\mathrm{g}}=$ $27.2 \times 10^{-3} \mathrm{~W} \mathrm{~m}^{-1} \mathrm{~K}^{-1}$. Alumina cylinders with $d_{\mathrm{p}}^{\mathrm{e}}=5.9 \mathrm{~mm}$ were used as the packing material in the experiments. For a more detailed description of the set-up and procedure, see [25]. 

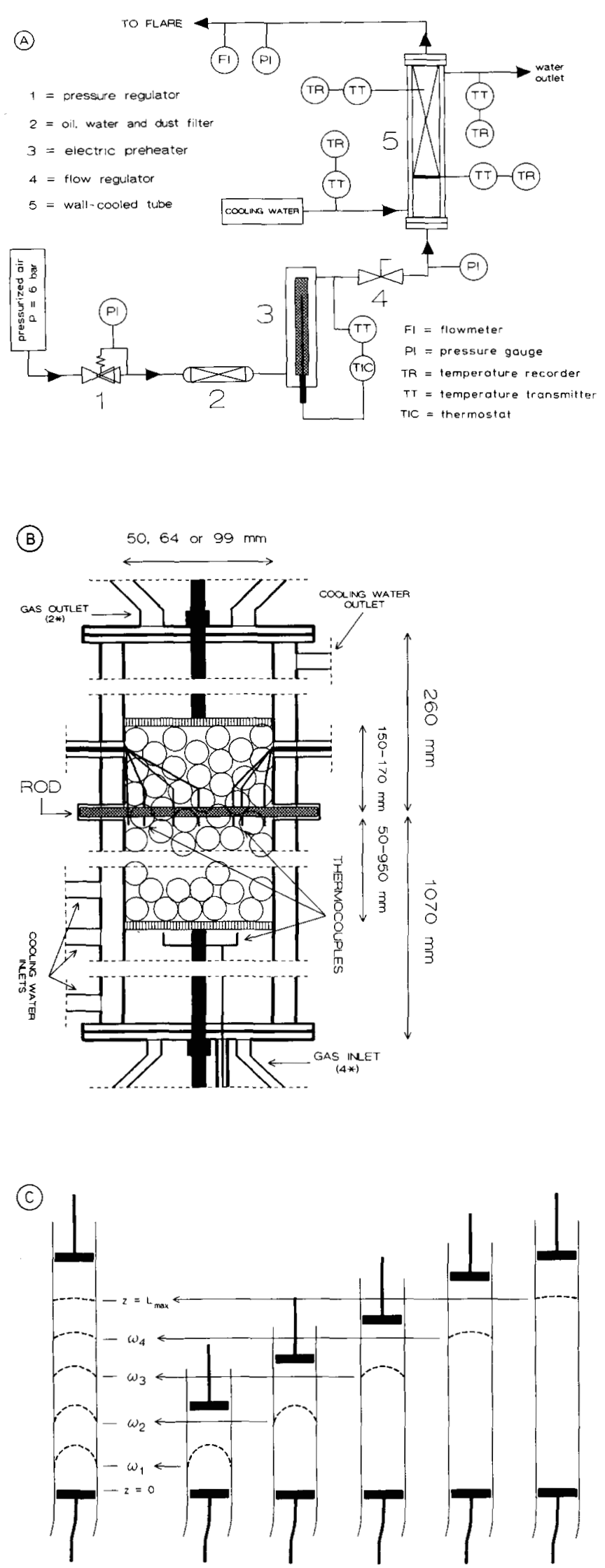

Fig. 1. A - Experimental set-up, B - Wall-cooled tube, C - Alteration of bed length.

\section{Discussion}

\subsection{Influence of the Boundary Condition at Outlet}

The influence of the boundary condition at the outlet was studied in the presence of a parabolic radial inlet temperature profile given by Eq. (5a). Different results were obtained from the model calculations when a radial outlet temperature profile according to Eq. (6a) was assumed than when taking the second derivative of temperature in the axial direction equal to zero as given by Eq. $(6 \mathrm{c})$. This is shown in Fig. 2. Fig. 2a was calculated with Eqs (3), (4), (5a) and a fixed outlet temperature profile Eq. (6a), for arbitrarily chosen values of model parameters. Fig. $2 b$ was calculated with the outlet boundary condition given by Eq. $(6 c)$ for the same values of the model parameters. If a fixed radial temperature profile at the outlet is assumed, large axial gradients are observed at the outlet. The influence of the outlet boundary conditions, given by Eqs (6a) and $(6 \mathrm{c})$, becomes very clear if the effective axial thermal conductivity and the resistance to radial heat transport are assumed to be very high. This situation is illustrated in Fig. 3 for arbitrarily chosen values of model parameters. If a fixed radial outlet temperature profile is chosen, large axial gradients prevail, despite the radial heat transport being low.

The choice of the axial position $\omega_{\text {out }}$ at which the outlet boundary conditions, given by Eqs (6b) and $(6 \mathrm{c})$, can be used is important. The smallest value of $\omega_{\text {out }}$ has to be found for which the temperatures calculated for the packed

(A)
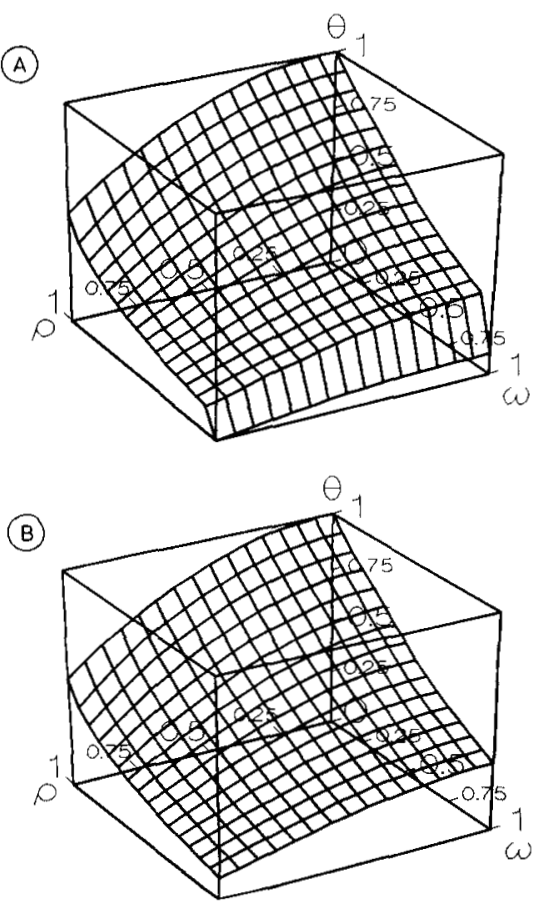

Fig. 2. Temperature profiles calculated with Eqs (3), (4) and (5a) for $A=0.5, \mathrm{Bo}_{\mathrm{h}, \mathrm{r}}^{\Theta}=2.5, \mathrm{Bi}_{\mathrm{t}}=3.0$ and $\mathrm{Pe}_{\mathrm{h}, \mathrm{a}}^{\Theta}=1000$. A - Outlet boundary condition given by Eq. (6a) with $B=C=0.1, \mathrm{~B}$ - Outlet boundary condition given by Eq. $(6 \mathrm{c})$ with $\omega_{\text {out }}=1.0$. 
(A)
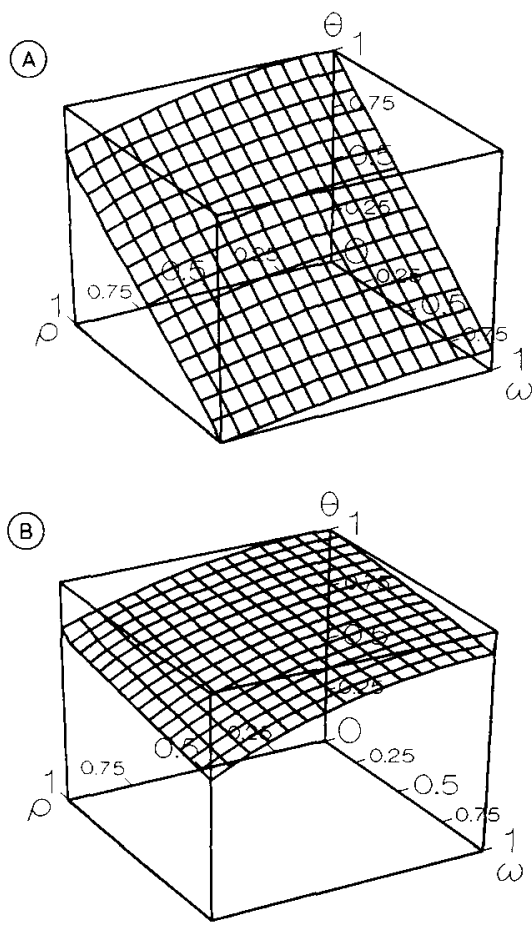

Fig. 3. Temperature profiles calculated with Eqs (3), (4) and (5a) for $A=0.2, \mathrm{Bo}_{\mathrm{h}, \mathrm{r}}^{\Theta}=10, \mathrm{Bi}_{\mathrm{t}}=1.0$ and $\mathrm{Pe}_{\mathrm{h}, \mathrm{a}}^{\Theta}=0.1 . \mathrm{A}$ - Outlet boundary condition given by Eq. (6a) with $B=C=0.1, B$ - Outlet boundary condition given by Eq. (6c) with $\omega_{\text {out }}=1.0$.

bed are no longer influenced by the exact value of $\omega_{\text {out }}$. To this end, temperature profiles are calculated with Eqs (6b) and $(6 \mathrm{c})$ for certain values of model parameters and different values of $\omega_{\text {out }}$. The values used for the model parameters are: $A=0, \quad \mathrm{Bo}_{\mathrm{h}, \mathrm{r}}^{\Theta}=3.0, \quad \mathrm{Bi}_{\mathrm{t}}=5.0$ and $\mathrm{Pe}_{\mathrm{h}, \mathrm{a}}^{\Theta}=10000,100$ and 10. The influence of the choice of $\omega_{\text {out }}$ was studied by examining the differences in the calculated temperatures at $\omega=1$ and $\varrho=0,0.4,0.7$ and 1.0 , for $\omega_{\text {out }}=a$ and $\omega_{\text {out }}=a+0.1$, respectively. Starting with a value of $a=1$ and increasing this value by 0.1 at each step, the differences are calculated as follows:

$$
\begin{aligned}
\operatorname{Diff}\left(\omega_{\text {out }}=a\right)= & 0.25\left[\frac{\left[\theta_{0}(a+0.1)-\theta_{0}(a)\right]}{\theta_{0}(a)}+\right. \\
& +\frac{\left[\theta_{0.4}(a+0.1)-\theta_{0.4}(a)\right]}{\theta_{0.4}(a)}+
\end{aligned}
$$

$$
\begin{aligned}
& +\frac{\left[\theta_{0.7}(a+0.1)-\theta_{0.7}(a)\right]}{\theta_{0.7}(a)}+ \\
& \left.+\frac{\left[\theta_{1}(a+0.1)-\theta_{1}(a)\right]}{\theta_{1}(a)}\right] 100 \% .
\end{aligned}
$$

In Eq. (8), $\theta_{\mathrm{b}}(a)$ is the calculated temperature at $\omega=1$ and $\varrho=b$, with Eq. (6b) or Eq. (6c) taken at the axial position $\omega_{\text {out }}=a$. Table 1 lists the calculated differences for $a=1.0-1.5$. It can be seen from this table that the axial position, where Eq. (6b) or (6c) is adopted as the outlet boundary condition, without influencing the profiles calculated for $0<\omega<1$, increases with decreasing $\mathrm{Pe}_{\mathrm{h}, \mathrm{a}}^{\Theta}$, as expected. It can also be seen that, for a very wide range of $\mathrm{Pe}_{\mathrm{h}, \mathrm{a}}^{\Theta}$, Eq. (6c) can be safely taken at $\omega_{\text {out }}=1$, whereas $\omega_{\text {out }}>1.5$ is needed for Eq. (6b). Therefore, Eq. (6c) is preferred to Eq. (6b) as the outlet boundary condition. However, it should be realized that Eq. (6c) is an "open" boundary condition, which is fundamentally different from a closed one.

\subsection{Significance of Axial Dispersion of Heat}

The numerical solution of Eqs (3), (4), (5a) and (6c) was fitted to experimental temperature profiles. This produced $\lambda_{\mathrm{e}, \mathrm{a}}, \lambda_{\mathrm{e}, \mathrm{r}}$ and $\alpha_{\mathrm{w}}$ values for three wall-cooled tubes, differing only in inner diameter and filled with alumina cylinders, applying different gas flow rates. The obtained results are listed in Table 2 together with the so-called goodness of fit (GOF) data and the mean absolute error. GOF is the probability that the chi-square value exceeds a particular value $\chi_{\min }^{2}$ by chance. This probability is calculated using the chisquare distribution for $n-m$ degrees of freedom, where $n$ is the number of measured points and $m$ the number of adjustable parameters. If GOF shows a very small probability for some particular data set, the apparent discrepancies are unlikely to be coincidental fluctuations. In this case, either the model is incorrect or the measurement errors are actually larger than stated [24]. The mean absolute error is calculated according to:

$$
\text { Error }=\frac{\sum_{i=1}^{n} \operatorname{abs}\left[\theta_{\mathrm{i}}-\theta\left(\varrho, \omega, \lambda_{\mathrm{e}, \mathrm{r}}, \lambda_{\mathrm{e}, \mathrm{a}}, \alpha_{\mathrm{w}}\right)\right]}{\sum_{i=1}^{n} \theta_{\mathrm{i}}} 100 \%
$$

\begin{tabular}{|c|c|c|c|c|c|c|c|}
\hline & & $a=1.0$ & $a=1.1$ & $a=1.2$ & $a=1.3$ & $a=1.4$ & $a=1.5$ \\
\hline Boundary condition Eq. (6b) & $\begin{array}{lr}\mathrm{Pe}_{\mathrm{h}, \mathrm{a}}^{\Theta}= & 10 \\
\mathrm{Pe}_{\mathrm{h}, \mathrm{a}}^{\Theta}= & 100 \\
\mathrm{Pe}_{\mathrm{h}, \mathrm{a}}^{\Theta}=10000\end{array}$ & & $\begin{array}{r}35.22 \% \\
5.13 \% \\
0.53 \%\end{array}$ & $\begin{array}{l}9.18 \% \\
0.26 \% \\
0.01 \%\end{array}$ & $\begin{array}{r}2.96 \% \\
0.01 \% \\
<0.01 \%\end{array}$ & $\begin{array}{r}1.01 \% \\
<0.01 \%\end{array}$ & $0.36 \%$ \\
\hline Boundary condition Eq. $(6 \mathrm{c})$ & $\begin{array}{lr}\mathrm{Pe}_{\mathrm{h}, \mathrm{a}}^{\Theta}= & 10 \\
\mathrm{Pe}_{\mathrm{h}}^{\Theta}= & 100 \\
\mathrm{Pe}_{\mathrm{h}, \mathrm{a}}^{\mathrm{a}}=10000\end{array}$ & $\begin{array}{l}<0.01 \% \\
<0.01 \% \\
<0.01 \%\end{array}$ & & & & & \\
\hline
\end{tabular}

Table 1. Temperature differences at $\omega=1$ calculated with Eqs (3), (4), (5a) and (6b) or (6c), respectively, for different values of $\omega_{\text {out }}$. Model parameters: $A=0, \mathrm{Bo}_{\mathrm{h}, \mathrm{r}}^{\Theta}=3.0, \mathrm{Bi}_{\mathrm{t}}=5.0$. 
Table 2. Dimensionless best fit values for $\lambda_{e, a}, \lambda_{e, r}$ and $\alpha_{\mathrm{w}}$ for experiments with alumina cylinders of $d_{\mathrm{p}}^{s}=5.9 \mathrm{~mm}$, for three different tube diameters and at different gas flow rates. Calculations performed with Eqs (3), (4), (5a) and (6c), i.e. using a parabolic temperature profile at inlet.

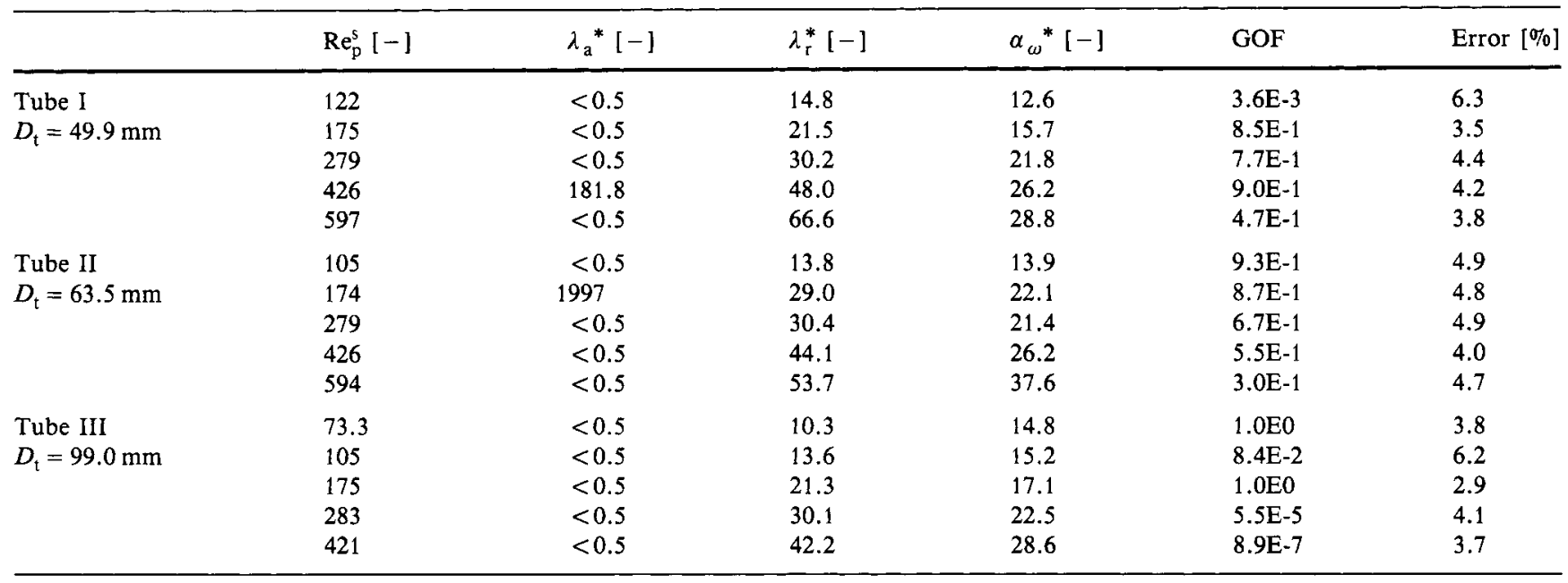

For most of the performed fit a very small effective axial thermal conductivity, $<0.01 \mathrm{~W} \mathrm{~m}^{-1} \mathrm{~K}^{-1}$, was obtained. The values found for $\lambda_{\mathrm{e}, \mathrm{r}}$ and $\alpha_{\mathrm{w}}$ are practically equal to those obtained with an analytically solved model in which axial heat dispersion was neglected [26]. Only occasionally, was $\lambda_{e, a}$ very high, namely $>10 \mathrm{~W} \mathrm{~m}^{-1} \mathrm{~K}^{-1}$. In this case, the values of $\lambda_{\mathrm{e}, \mathrm{r}}$ and $\alpha_{\mathrm{w}}$ are somewhat higher than those obtained from the model with axial dispersion neglected. An occasionally very high $\lambda_{\mathrm{e}, \mathrm{a}}$ may be caused by two phenomena. Firstly, the model calculations are quite insensitive to the value of $\lambda_{e, a}$. This is seen in Fig. 4 which shows the target function calculated with Eq. (7) for the tube with $D_{\mathrm{t}}=63.5 \mathrm{~mm}$, filled with alumina cylinders of $d_{\mathrm{p}}^{\mathrm{e}}=5.9 \mathrm{~mm}$ and at a Reynolds number of $\operatorname{Re}_{\mathrm{p}}^{\mathrm{s}}=174$. Moreover, $\lambda_{\mathrm{e}, \mathrm{a}}$ is cross-correlated with $\lambda_{\mathrm{e}, \mathrm{r}}$ and $\alpha_{\mathrm{w}}$. This is shown in Fig. 5, where temperature profiles calculated with Eqs (3), (4), (5a) and (6c) are plotted for the best fit heat transfer coefficients under the same conditions as in Fig. 4. Fig. $5 \mathrm{a}$ is calculated with the best fit values for $\lambda_{\mathrm{e}, \mathrm{r}}$ and $\alpha_{\mathrm{w}}$, neglecting axial dispersion of heat and Fig. $5 \mathrm{~b}$ shows the best fit values for all three coefficients, see also Table 2 . These diagrams indicate that almost the same temperature profiles are calculated for completely different values of $\lambda_{\mathrm{e}, \mathrm{a}}$, provided that the values of $\lambda_{\mathrm{e}, \mathrm{r}}$ and $\alpha_{\mathrm{w}}$ are slightly adjusted. The mean difference between the two profiles as calculated with Eq. (9) is only $4.5 \%$, which is practically the same as the difference between the measured and fitted profiles, see Table 2 . If the temperature profile in axial direction is not completely smooth and/or the inlet temperature profile is not read correctly, it is possible to obtain a slightly better fit with a very high value of $\lambda_{e, a}$ together with somewhat higher values of $\lambda_{e, r}$ and $\alpha_{w}$, compared to the conditions where axial heat dispersion is neglected.

The above considerations lead to the conclusion that axial dispersion of heat does not improve the description of heat transport in wall-cooled packed beds, for the conditions applied here. To verify this, a one parameter fit, in which only $\lambda_{\mathrm{e}, \mathrm{a}}$ was adjusted, was also performed on all the temperature profiles available, using the best fit values for $\lambda_{\mathrm{e}, \mathrm{r}}$ and $\alpha_{\mathrm{w}}$ as obtained with the model which neglected the axial

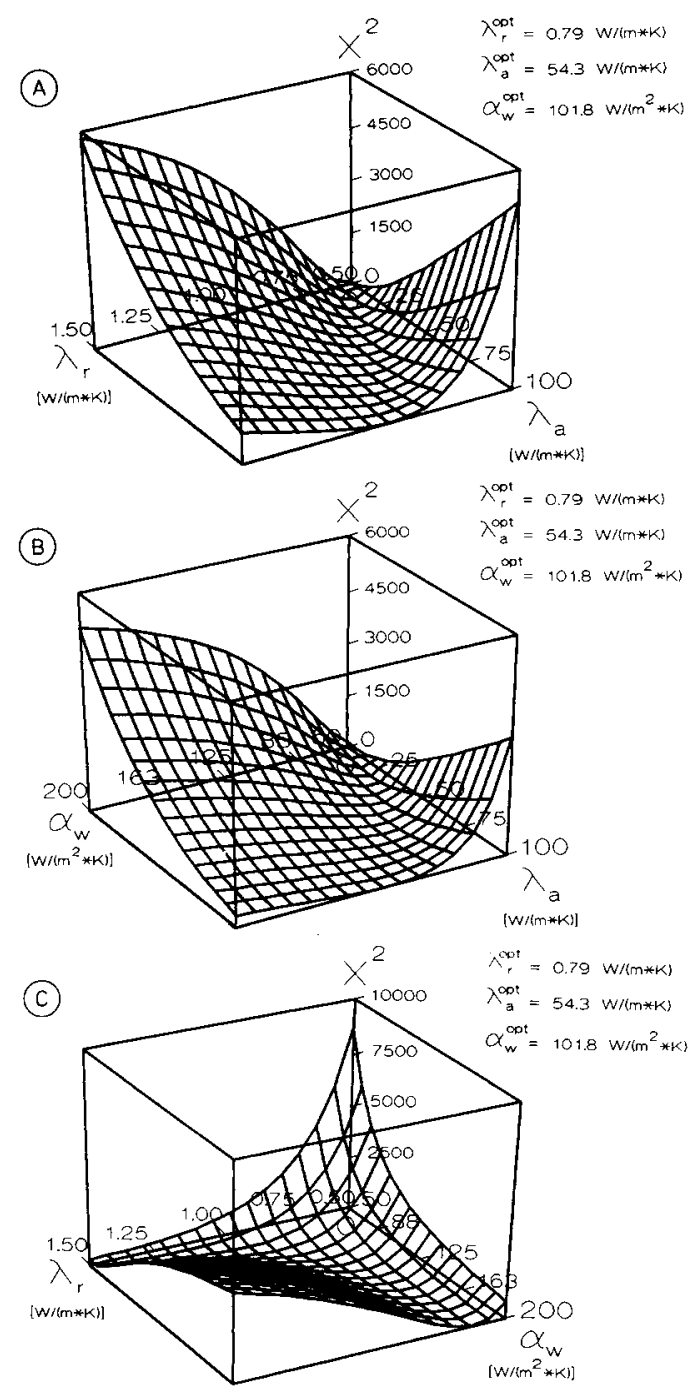

Fig. 4. Target function $\chi^{2}$ calculated for the tube with $D_{\mathrm{t}}=63.5 \mathrm{~mm}$, filled with alumina cylinders of $d_{\mathrm{p}}^{\mathrm{e}}=5.9 \mathrm{~mm}$ and $\mathrm{Re}_{\mathrm{p}}^{\mathrm{s}}=174$. A $-\chi^{2}$ as a function of $\lambda_{e, a}$ and $\lambda_{e, r}$ for $\alpha_{\mathrm{w}}=120 \mathrm{Wm}^{-2} \mathrm{~K}^{-1}, \mathrm{~B}-\chi^{2}$ as a function of $\lambda_{e, a}$ and $\alpha_{w}$ for $\lambda_{e, r}=0.97 \mathrm{~W} \mathrm{~m}^{-1} \mathrm{~K}^{-1}, \mathrm{C}-\chi^{2}$ as a function of $\lambda_{e, r}$ and $\alpha_{\mathrm{w}}$ for $\lambda_{\mathrm{e}, \mathrm{a}}=46.7 \mathrm{~W} \mathrm{~m}^{-1} \mathrm{~K}^{-1}$. 


\section{(A)}

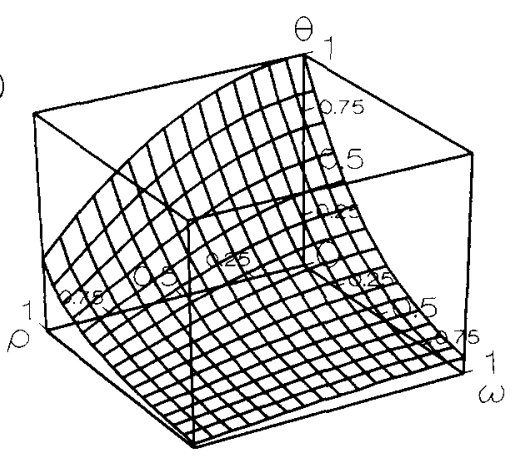

(B)

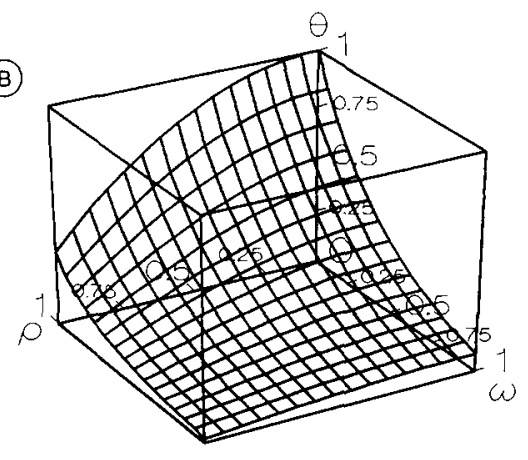

Fig. 5. Temperature profiles, calculated with Eqs (3), (4), (5a) and (6c) for best fit values of model parameters; conditions the same as in Fig. 4. $\mathrm{A}-$ For $\mathrm{Pe}_{\mathrm{h}, \mathrm{a}}=\infty, \mathrm{Bo}_{\mathrm{h}, \mathrm{r}}^{\Theta}=1.46$ and $\mathrm{Bi}_{\mathrm{t}}=4.69, \mathrm{~B}-$. For $\mathrm{Pe}_{\mathrm{h}, \mathrm{a}}=7.55, \mathrm{Bo}_{\mathrm{h}, \mathrm{r}}^{\Theta}=1.05$ and $\mathrm{Bi}_{\mathrm{t}}=4.10$.

dispersion of heat. Thus obtained values for $\lambda_{e, a}$ were again very small (under $0.01 \mathrm{~W} \mathrm{~m}^{-1} \mathrm{~K}^{-1}$ ), yielding $\mathrm{Pe}_{\mathrm{a}, \mathrm{h}}$ values of at least 50.

The above can also be shown graphically by taking a certain value of $\lambda_{e, a}$ and adjusting only $\lambda_{e, r}$ and $\alpha_{w}$ in such a way that best fit is obtained with the numerical solution of Eqs (3), (4), (5a) and (6a) or (6c), respectively. This is shown in Fig. 6 for the experiments in the tube with $D_{\mathrm{t}}=99.0 \mathrm{~mm}$, filled with alumina cylinders of $d_{\mathrm{p}}^{\mathrm{e}}=5.9 \mathrm{~mm}$ and for $\mathrm{Re}_{\mathrm{p}}^{\mathrm{s}}=421$. Fig. $6 \mathrm{a}$ presents the target function $\chi^{2}$ plotted against the dimensionless effective axial thermal conductivity. The target function is reduced by dividing it by the target function for $\lambda_{\mathrm{e}, \mathrm{a}}=0$. The two lines in the diagram are calculated for two different outlet boundary conditions, namely either with a fixed radial outlet temperature profile given by Eq. (6a) or taking the second derivative of temperature as zero in the axial direction at $\omega=1$ as given by Eq. (6c). As seen from Fig. 6 a, the target function increases only slightly with a large increase in $\lambda_{e, a}$, but this increase in the target function is larger when Eq. (6c) is adopted as the outlet boundary condition.

Figs $6 \mathrm{~b}$ and $6 \mathrm{c}$ present the best fitted dimensionless effective radial conductivity and wall heat transfer coefficient, respectively. As a rule, both coefficients increase slightly with increasing effective axial conductivity.

Fig. 7 shows the same profiles as Fig. 6 for the tube with $D_{\mathrm{t}}=63.5 \mathrm{~mm}$ and $\mathrm{Re}_{\mathrm{p}}^{\mathrm{s}}=174$, calculated with the outlet
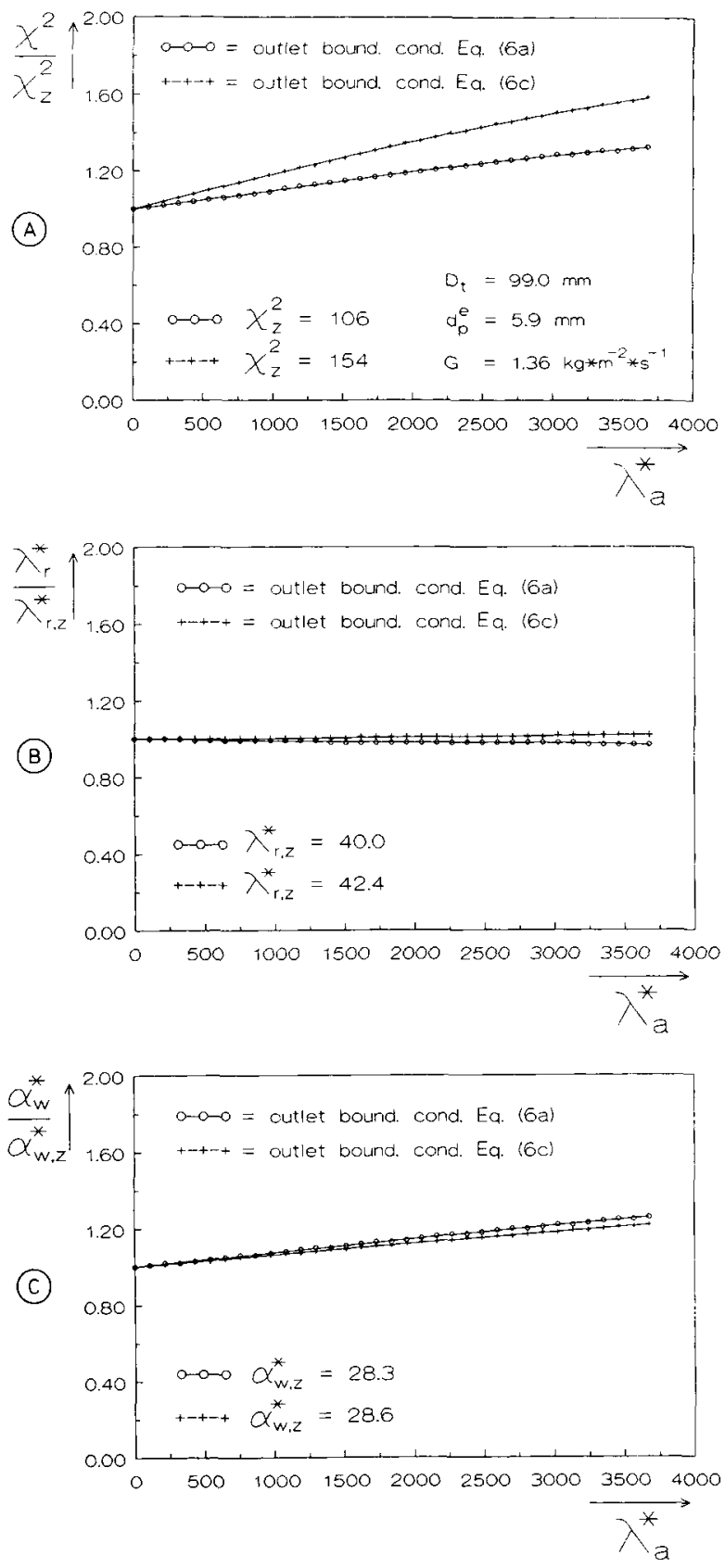

Fig. 6. Target function $\chi^{2}$ and regression values for $\lambda_{e, r}$ and $\alpha_{w}$ as functions of $\lambda_{\mathrm{e}, \mathrm{a}}$ for a tube with $D_{\mathrm{t}}=99.0 \mathrm{~mm}$ and $\mathrm{Re}_{\mathrm{p}}^{\mathrm{s}}=421$. A Target function, B - Effective radial thermal conductivity, C - Wall heat transfer coefficient.

boundary condition given by Eq. (6c). In this experiment, the target function reached a minimum at $\lambda_{\mathrm{a}}^{*}=1997$, see also Table 2. However, this minimum is not very pronounced as seen from Fig. $7 \mathrm{a}$. It should be realized that $\lambda_{\mathrm{a}}^{*}=\mathrm{Re} \mathrm{p} \mathrm{Pr} / \mathrm{Pe}_{\mathrm{a}, \mathrm{h}}$, where in our case $\operatorname{Pr}=0.71$. For axial mass dispersion in the turbulent regime, say for $\operatorname{Re}_{\mathrm{p}}^{\mathrm{s}}>50$, the axial Peclet number was found to be between 1 and 2 . If we also assume that, for axial heat dispersion, the Peclet number does not become less than unity, the relevant range for $\lambda_{\mathrm{a}}^{*}$ in Fig. 7 is $0<\lambda_{\mathrm{a}}^{*}<123$. 

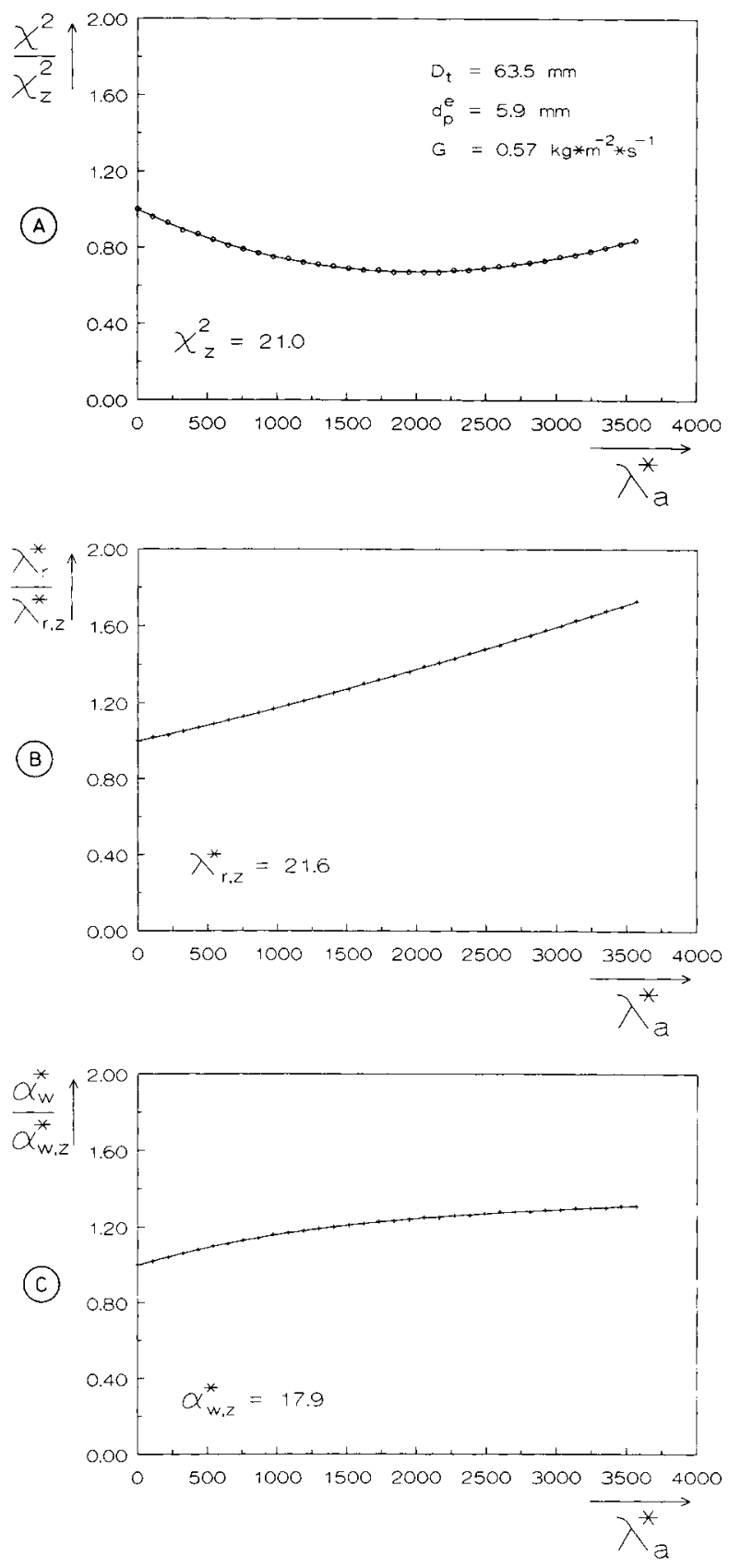

Fig. 7. The same profiles as in Fig. 6 for a tube with $D_{\mathrm{t}}=63.5 \mathrm{~mm}$ and $\operatorname{Re}_{\mathrm{p}}^{\mathrm{s}}=174$. A - Target function, B - Effective radial thermal conductivity, C - Wall heat transfer coefficient.

\subsection{Influence of the Boundary Condition at Inlet}

So far, only a fixed radial temperature profile as given by Eq. ( 5 a) has been used as the inlet boundary condition. With this condition, no significant improvement was obtained by incorporating axial heat dispersion. Let us now consider the consequence of assuming the inlet temperature profile to be radially constant while the actual profile is curved. In addition, let us examine the effect of a Danckwerts type inlet boundary condition.

\section{- Flat radial inlet temperature profile}

The measured radial temperature profiles at the axial position $\omega=0$ were always parabolic in shape, yielding values for the constant $A$ in Eq. (5a) of between 0.5 and 0.8 . Measuring the temperature only at the centre of the bed and assuming it to be constant over the radius, the inlet boundary condition given by Eq. ( 5 a) transforms into:

$\omega=0$, all $\varrho, \quad \theta=1$.

This inlet boundary condition is often used in literature as that for an open system. Values of $\lambda_{\mathrm{e}, \mathrm{r}}, \lambda_{\mathrm{e}, \mathrm{a}}$ and $\alpha_{\mathrm{w}}$ can again be obtained by fitting the solution of Eqs (3), (4), (6c) and $(10)$ to the experimental temperature profiles. Table 3 lists the results for the three tubes, filled with alumina cylinders, at different gas flow rates. Remarkably, now the optimum values of $\lambda_{\mathrm{e}, \mathrm{a}}$ are no longer around zero and an improvement in the description of the temperature profiles is achieved by inclusion of axial dispersion of heat. Comparing the results of Table 3 with those in Table 2, it can be seen that the values of $\lambda_{\mathrm{e}, \mathrm{r}}$ and $\alpha_{\mathrm{w}}$ are slightly higher. Probably, the large axial temperature gradients, especially near the inlet and near the wall of the tubes, introduced by overestimation of inlet temperature, lead to an apparent axial thermal conductivity.

\section{- Danckwerts inlet boundary condition.}

As already pointed out, assumption of a temperature jump at $\omega=0$ is unusual with our set-up, because the inlet profile is taken at a location within the packed bed. However, since Eq. (5b) is often used in literature, its effect on $\lambda_{\mathrm{e}, \mathrm{a}}$ was studied. As expected, if constant $A$ (in Eq. (5b)) was obtained by fitting a parabola to the measured temperature profile at $\omega=0$, the fitting of the model including axial dispersion, using Eq. (5b) as the inlet boundary condition, nearly always yielded very small values for $\lambda_{\mathrm{e}, \mathrm{a}}$. If the temperature profile at $\omega=0$ is again assumed to be radially flat, Eq. (5b) transforms into:

$\frac{\partial \theta}{\partial \omega}=-\mathrm{Pe}_{\mathrm{h}, \mathrm{a}}^{\Theta}(1-\theta)$.

Again, values for $\lambda_{e, r}, \lambda_{e, a}$ and $\alpha_{w}$ can be obtained by fitting the numerical solution of Eqs (3), (4), (6c) and (11) to experimental temperature profiles. Table 4 lists the results obtained for the three different tubes, filled with alumina cylinders of $d_{\mathrm{p}}^{\mathrm{e}}=5.9 \mathrm{~mm}$ and the corresponding values of $\mathrm{Re}_{\mathrm{p}}^{\mathrm{s}}$. Again, discrete values were obtained for the effective axial conductivity and even a good fit as follows from the high values for GOF and low mean errors. Thus, incorporation of axial dispersion into the heat balance and using a Danckwerts inlet boundary condition leads to an apparent improvement in the description of heat transport in wallcooled packed beds, in the case of incorrectly assuming a radially flat temperature profile immediately in front of the inlet while the actual profile is curved.

Elsewhere [27], we have shown that adoption of a radially flat inlet temperature profile, while the actual profile is 
curved, may imply a length dependence of $\lambda_{e, r}$ and $\alpha_{w}$. This is due to overestimation of temperature at the inlet, in the case of cooling. The inlet boundary condition, given by Eq. (11), can compensate for this overestimation, by introducing a temperature jump at the inlet. This is illustrated by the pseudo-homogeneous one-dimensional model for the description of heat transport in wall-cooled packed beds. The well-known solution of this model is given by:

$\theta^{\mathrm{MC}}=\theta_{0}^{\mathrm{MC}} \exp \left(-4 \mathrm{St}^{\theta} \omega\right)$.

In Eq. (12), $\theta^{\mathrm{MC}}$ is the so-called "mean-cup" averaged temperature, calculated according to:

$\theta^{\mathrm{MC}}=2 \int_{0}^{1} \varrho \theta d \varrho$ and $\theta=\left(T-T_{\mathrm{w}}\right) /\left(T_{0}-T_{\mathrm{w}}\right)$, where $T_{0}$ is the temperature measured in the centre of the packed bed at $\omega=0$. If the temperature profile at $\omega=0$ is radially flat, $\theta_{0}^{\mathrm{MC}}$ equals unity, otherwise it would be less than one. Let us assume that the actual axial mean-cup temperature profile, measured in the packed bed, can be described by the following equation:

$$
\theta^{\mathrm{MC}}=0.7 \exp (-2 \omega) \text {. }
$$

Thus, $\theta_{0}^{\mathrm{MC}}=0.7$ and $\mathrm{St}^{\Theta}=0.5$.

Now, assuming that this profile is described by Eq. (12), incorrectly taking the inlet temperature profile to be radially flat, or:

$\theta^{\mathrm{MC}}=\exp \left(-4 \mathrm{St}^{\Theta} \omega\right)$.

Table 3. Dimensionless best fit values for $\lambda_{\mathrm{e}, \mathrm{a}}, \lambda_{\mathrm{e}, \mathrm{r}}$ and $\alpha_{\mathrm{w}}$ for alumina cylinders, for three different tube diameters and at different gas flow rates. Calculations performed with Eqs (3), (4), (6c) and (10), whereby a radially flat inlet temperature profile was incorrectly assumed.

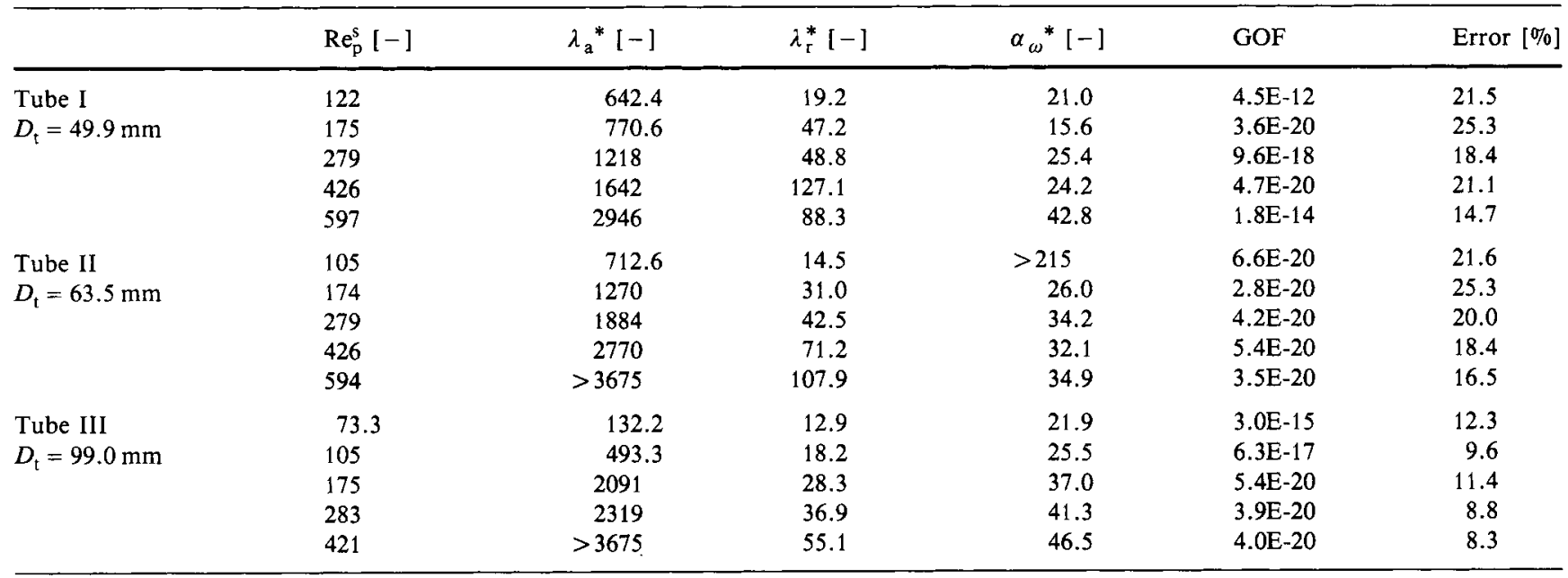

Table 4. Dimensionless best fit values for $\lambda_{e, a}, \lambda_{e, r}$ and $\alpha_{w}$ for alumina cylinders, for three different tube diameters and at different gas flow rates. Calculations performed with Eqs (3), (4), (6c) and (11) using a Danckwerts inlet boundary condition and incorrectly assuming a radially flat temperature profile directly in front of the inlet

\begin{tabular}{|c|c|c|c|c|c|c|}
\hline & $\operatorname{Re}_{\mathrm{p}}^{\mathrm{s}}[-]$ & $\lambda_{\mathbf{a}}^{*}[-]$ & $\lambda_{\mathrm{r}}^{*}[-]$ & $\alpha_{\omega}^{*}[-]$ & GOF & Error $[\%]$ \\
\hline Tube I & 122 & 611.6 & 18.7 & 16.4 & $2.6 \mathrm{E}-2$ & 8.2 \\
\hline \multirow{3}{*}{$D_{\mathrm{t}}=49.9 \mathrm{~mm}$} & 175 & 1131 & 27.2 & 21.8 & $3.0 \mathrm{E}-2$ & 5.9 \\
\hline & 426 & 2950 & 56.5 & 34.2 & $1.0 \mathrm{E}-2$ & 7.3 \\
\hline & 597 & 3619 & 81.6 & 37.0 & $5.1 \mathrm{E}-1$ & 6.1 \\
\hline Tube II & 105 & 907.7 & 17.1 & 22.1 & $2.5 \mathrm{E}-1$ & 8.1 \\
\hline \multirow{2}{*}{$D_{\mathrm{t}}=63.5 \mathrm{~mm}$} & 426 & $>3675$ & 59.0 & 33.1 & $5.5 \mathrm{E}-2$ & 5.5 \\
\hline & 594 & $>3675$ & 74.8 & 41.7 & $8.2 \mathrm{E}-4$ & 6.0 \\
\hline Tube III & 73.3 & 662.7 & 12.6 & 20.0 & $9.4 \mathrm{E}-1$ & 5.4 \\
\hline \multirow{2}{*}{$D_{\mathrm{t}}=99.0 \mathrm{~mm}$} & 105 & 798.5 & 16.5 & 21.1 & 9.3E-1 & 5.6 \\
\hline & 175 & 1465 & 24.3 & 23.5 & $8.5 \mathrm{E}-1$ & 5.1 \\
\hline
\end{tabular}


The mean-cup temperature, calculated with Eq. (12b) can be set equal to the "measured" temperature described by Eq. (12a), at different bed lengths. This yields for example:

$\omega=0.2 \rightarrow \mathrm{St}^{\Theta}=0.95$ and $\omega=0.8 \rightarrow \mathrm{St}^{\Theta}=0.61$.

In other words, $\mathrm{St}^{\Theta}$ or $U_{\text {ov }}$ decreases with increasing bed length, i.e. manifesting the so-called "length effect".

Supposing that the profile, given by Eq. (12a), is described by a one-dimensional model with axial heat dispersion and using a Danckwerts inlet boundary condition: the dimensionless equation for this model can be written as follows:

$\frac{1}{\mathrm{Pe}_{\mathrm{h}, \mathrm{a}}^{\Theta}} \frac{\partial^{2} \theta^{\mathrm{MC}}}{\partial \omega^{2}}-\frac{\partial \theta^{\mathrm{MC}}}{\partial \omega}-4 \mathrm{St}^{\Theta} \theta^{\mathrm{MC}}=0$

Subject to:

$\omega=0, \frac{\partial \theta^{\mathrm{MC}}}{\partial \omega}=-\mathrm{Pe}_{\mathrm{h}, \mathrm{a}}^{\Theta}\left(1-\theta^{\mathrm{MC}}\right)$,

$\omega \rightarrow \infty, \quad \theta^{\mathrm{MC}}$ is bounded .

Eq. (14) is solved together with Eq. (15) to yield:

$$
\begin{aligned}
\theta^{\mathrm{MC}}= & \frac{2}{1+\sqrt{1+\frac{16 \mathrm{St}^{\Theta}}{\mathrm{Pe}_{\mathrm{h}, \mathrm{a}}^{\Theta}}} \times} \\
& \times \exp \left[0.5 \mathrm{Pe}_{\mathrm{h}, \mathrm{a}}^{\Theta}\left(1-\sqrt{1+\frac{16 \mathrm{St}^{\Theta}}{\mathrm{Pe}_{\mathrm{h}, \mathrm{a}}^{\Theta}}}\right) \omega\right]
\end{aligned}
$$

Eq. (16) can be fitted to the temperatures calculated with Eq. (12a), yielding best fit values for $\mathrm{St}^{\Theta}$ and $\mathrm{Pe} \mathrm{e}_{\mathrm{h}, \mathrm{a}}^{\Theta}$. Thereby, the following values are obtained:

$\mathrm{St}^{\Theta}=0.71$ and $\mathrm{Pe}_{\mathrm{h}, \mathrm{a}}^{\Theta}=4.67$.

The axial temperature profile calculated with Eq. (16) from these values can be mathematically proven to be exactly equal to the profile described by Eq. (12a). It should be noted that Eq. (16) was derived by incorrectly assuming that $\theta_{0}^{\mathrm{MC}}$ equals unity, as expressed by Eq. (15a). Thus, the temperature drop at the inlet caused by dispersion at low values of $\mathrm{Pe}_{\mathrm{h}, \mathrm{a}}^{\Theta}$ can compensate for the overestimation of the actual inlet temperature. The value found for $U_{\mathrm{ov}}$ is a factor of $1 / \theta_{\mathrm{o}}^{\mathrm{MC}}$ higher than the actual value. If Eq. (16) is fitted to the "measured" temperatures calculated with Eq. (12a) at different axial positions, no length dependence of $\mathrm{St}^{\Theta}$ or $U_{\mathrm{ov}}$ is observed. The above is illustrated in Fig. 8.

Similar results to those with the Danckwerts inlet boundary condition are obtained if the following inlet boundary condition is used instead:

$\omega \rightarrow-\infty$, all $\varrho, \quad \theta=1$.

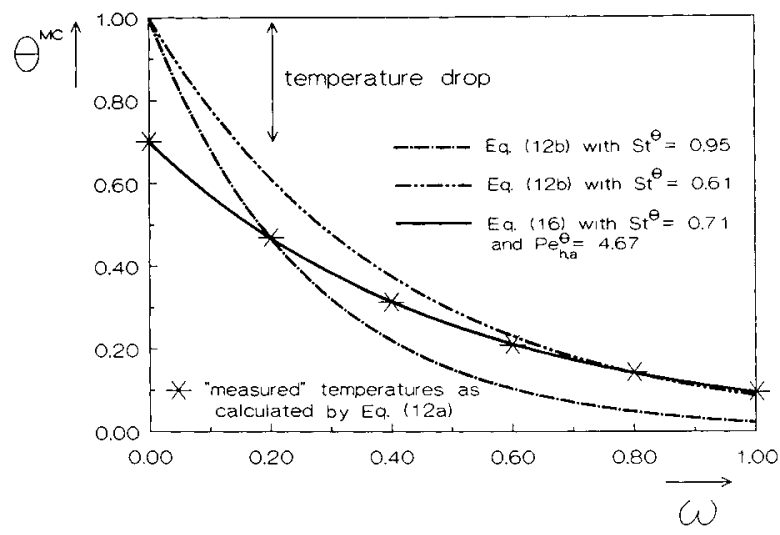

Fig. 8. Illustration of elimination of the so-called "length effect" of heat transport coefficients, applying the outlet boundary condition given by Eq. (11).

Eq. (17) is often employed in literature to obtain an analytical solution of Eq. (3). Also, now the temperature at $\omega=0$ is lowered by increasing the value of $\lambda_{e, a}$, thereby compensating for the overestimation of the temperature at $\omega=0$ in the case of cooling. This was also observed by Dixon [19] in the case of heating. He solved this problem by taking into account heat leakage to the section of the bed where $\omega<0$. Thus, inclusion of axial heat dispersion was no longer needed to eliminate the apparent length dependence of $\lambda_{\mathrm{e}, \mathrm{r}}$ and $\alpha_{\mathrm{w}}$.

\section{Conclusions}

The inclusion of axial dispersion of heat in the heat balance does not significantly improve the description of heat transport without reaction in wall-cooled or heated packed beds, if the correct radial inlet temperature profile is used and the employed Reynolds numbers exceed 50 . Only occasionally, an extremely high effective axial thermal conductivity is found which yields a slightly better fit. The sensitivity of model calculations to the effective axial thermal conductivity is very low and this parameter is cross-correlated with the effective radial thermal conductivity and the wall heat transfer coefficient. This leads to the conclusion that it is not possible to obtain reliable values for the effective axial conductivity from cold-flow experiments in wall-cooled or heated packed beds.

Although axial dispersion of heat can as a rule be neglected in the description of steady-state experiments in wall-cooled or heated packed beds, it cannot be neglected, e.g. if a dynamic heat transport process is described by a pseudohomogeneous model. In this case, axial dispersion of heat is needed to take into account the influence of the particleto-gas heat transfer coefficient $[28,29]$.

If axial dispersion is included, the following expression for the outlet boundary condition is proposed, to interpret cold-flow experiments:

$\omega=1$, all $\varrho, \frac{1}{\mathrm{Pe}_{\mathrm{h}, \mathrm{a}}^{\Theta}} \frac{\partial^{2} \theta}{\partial \omega^{2}}=0$. 
No physical justification exists for this boundary condition, see also Kalthoff and Vortmeyer [30], but it gave good results. The influence of this boundary condition on calculated temperatures in the packed bed is always very small, compared to e.g. setting the first derivative equal to zero at a certain axial position outside the packed bed. The latter is, for the system studied, equivalent to setting the outlet temperature equal to that of the coolant at that location. Furthermore, for this boundary condition, model calculations are more sensitive to the value of the axial dispersion coefficient, compared to the conditions given by Eqs (6a) and (6b).

Discrete values of the effective axial conductivity are obtained if the temperature measured in the centre of the packed bed at $\omega=0$ is adopted as the inlet temperature, assuming a flat radial temperature profile at this axial position, while the actual profile is curved. If, in this case, a Danckwerts boundary condition is used, values are also found for $\lambda_{\mathrm{e}, \mathrm{a}}$ and an apparent improvement in the description of the experimental temperature profiles is observed. This is due to the fact that the temperature drop at the inlet can compensate for the overestimation of inlet temperature, in the case of cooling. This temperature drop at the inlet may also apparently eliminate the length dependence of the radial heat transfer coefficients. Thus obtained coefficients slightly differ from the true values.

Thus, when modelling heat transport in wall-cooled or heated packed beds, adequate attention must be given to the choice of the inlet boundary condition, especially if axial heat dispersion is taken into account. If possible, the radial temperature profile, measured at a given position in the packed bed, should be used as the inlet temperature profile.

Received: September 19, 1991 [CET 427]

\section{Appendix}

The following set of equations is to be solved:

$$
\frac{\partial \theta}{\partial \omega}-\frac{1}{\mathrm{Pe}_{\mathrm{h}, \mathrm{a}}^{\Theta}} \frac{\partial^{2} \theta}{\partial \omega^{2}}-\frac{1}{\mathrm{Bo}_{\mathrm{h}, \mathrm{r}}^{\Theta}} \frac{1}{\varrho} \frac{\partial}{\partial \varrho}\left(\varrho \frac{\partial \theta}{\partial \varrho}\right)=0 .
$$

Subject to:

$$
\begin{aligned}
& \varrho=0, \text { all } \omega, \quad \frac{\partial \theta}{\partial \varrho}=0, \\
& \varrho=1, \quad \text { all } \omega, \quad \frac{\partial \theta}{\partial \varrho}=-\mathrm{Bi}_{\mathrm{t}} \theta, \\
& \omega=0, \text { all } \varrho, \quad \theta=1-A \varrho^{2}, \\
& \omega=1, \quad \text { all } \varrho, \quad \frac{1}{\mathrm{Pe}_{\mathrm{h}, \mathrm{a}}^{\Theta}} \frac{\partial^{2} \theta}{\partial \omega^{2}}=0 .
\end{aligned}
$$

Eq. (3) can also be written as

$$
\begin{aligned}
& \frac{\partial \theta}{\partial \omega}-\frac{1}{\mathrm{Pe}_{\mathrm{h}, \mathrm{a}}^{\Theta}} \frac{\partial^{2} \theta}{\partial \omega^{2}}=\mathrm{F}(\varrho, \omega), \\
& -\frac{1}{\mathrm{Bo}_{\mathrm{h}, \mathrm{r}}^{\Theta}} \frac{1}{\varrho} \frac{\partial}{\partial \varrho}\left(\varrho \frac{\partial \theta}{\partial \varrho}\right)=\mathrm{G}(\varrho, \omega)
\end{aligned}
$$

and

$\mathrm{F}(\varrho, \omega)+\mathrm{G}(\varrho, \omega)=0$.

Eq. (A 1) is solved with an upwind finite differences method and Eq. (A2) by an interior collocation method, subsequently both solutions being combined using Eq. (A 3).

\section{Finite Differences in Axial Direction}

For the first and second derivatives in axial direction, the following Taylor series are used:

$n=1, \frac{\partial \theta}{\partial \omega}=\frac{\theta_{\mathrm{m}}^{n}-\theta_{\mathrm{m}}^{n-1}}{h}+O(h)$

$2 \leq n \leq N+1, \frac{\partial \theta}{\partial \omega}=\frac{3 \theta_{\mathrm{m}}^{n}-4 \theta_{\mathrm{m}}^{n-1}+\theta_{\mathrm{m}}^{n-2}}{2 \mathrm{~h}}+O\left(h^{2}\right)$,

$1 \leq n \leq N, \quad \frac{\partial^{2} \theta}{\partial \omega^{2}}=\frac{\theta_{\mathrm{m}}^{n+1}-2 \theta_{\mathrm{m}}^{n}+\theta_{\mathrm{m}}^{n-1}}{h^{2}}+O\left(h^{2}\right)$.

In Eqs (A4) - (A 6), $N+2$ is the total number of axial finite difference points including the boundaries, thus: $h=L /(N+1)$. These Taylor series lead to the following set of difference equations for Eqs (A1), (5a) and (6c):

$n=0, \quad \theta_{\mathrm{m}}^{0}=1-A \varrho^{2}$,

$$
\begin{aligned}
n=1, & -\left(\frac{1}{h^{2} \mathrm{Pe}_{\mathrm{h}, \mathrm{a}}^{\Theta}}+\frac{1}{h}\right) \theta_{\mathrm{m}}^{0}+\left(\frac{2}{h^{2} \mathrm{Pe}_{\mathrm{h}, \mathrm{a}}^{\Theta}}+\frac{1}{h}\right) \theta_{\mathrm{m}}^{1}- \\
& -\left(\frac{1}{h^{2} \mathrm{Pe}_{\mathrm{h}, \mathrm{a}}^{\Theta}}\right) \theta_{\mathrm{m}}^{2}=F_{\mathrm{m}}^{1},
\end{aligned}
$$

$2 \leq n \leq N, \quad\left(\frac{1}{2 h}\right) \theta_{\mathrm{m}}^{n-2}-\left(\frac{1}{h^{2} \mathrm{Pe}_{\mathrm{h}, \mathrm{a}}^{\Theta}}+\frac{2}{h}\right) \theta_{\mathrm{m}}^{n-1}+$

$$
\begin{aligned}
& +\left(\frac{2}{h^{2} \mathrm{Pe}_{\mathrm{h}, \mathrm{a}}^{\Theta}}+\frac{3}{2 h}\right) \theta_{\mathrm{m}}^{n}- \\
& -\left(\frac{1}{h^{2} \mathrm{Pe}_{\mathrm{h}, \mathrm{a}}^{\Theta}}\right) \theta_{\mathrm{m}}^{n+1}=F_{\mathrm{m}}^{n},
\end{aligned}
$$




$$
\begin{aligned}
n=N+1, & \left(\frac{1}{2 h}\right) \theta_{\mathrm{m}}^{N-1}-\left(\frac{2}{h}\right) \theta_{\mathrm{m}}^{N+} \\
& +\left(\frac{3}{2 h}\right) \theta_{\mathrm{m}}^{N+1}=F_{\mathrm{m}}^{N+1}
\end{aligned}
$$

\section{Collocation in Radial Direction}

For the collocation method in radial direction, the following polynomial was chosen:

$$
\theta(\varrho, \omega)=a_{0}(\omega)+a_{1}(\omega) \varrho^{2}+\ldots+a_{M}(\omega) \varrho^{2 M}
$$

where $M+2$ is the total number of collocation points, including the boundaries. Eq. (4b) together with Eq. (A11) yields the following expression at $\varrho=1$ :

$\frac{\partial \theta_{\mathrm{M}+1}^{n}}{\partial \varrho}=2 a_{1}^{n}+\ldots+2 M a_{\mathrm{M}}^{n}=-\mathrm{Bi}_{\mathrm{t}} \theta_{\mathrm{M}+1}^{n}$

or

$\theta_{\mathrm{M}+1}^{n}=-\frac{2}{\mathrm{Bi}_{\mathrm{t}}} a_{1}^{n}-\ldots-\frac{2 M}{\mathrm{Bi}_{\mathrm{t}}} a_{\mathrm{M}}^{n}$.

Eq. (A 12) can be used to eliminate the term $a_{0}(\omega)$ from Eq. (A 11) and the following set of equations is obtained in the radial direction for the interior collocation points $\varrho_{1} \ldots \varrho_{\mathrm{M}}$ :
Substitution of Eq. (A 13) into Eq. (A 14) yields the desired relationships for $\theta_{\mathrm{m}}^{n}$ at every interior collocation point. For radial positions of these collocation points, those suggested by Villadsen and Stewart [31] were used. The obtained set of equations can be combined with Eqs (A7) - (A9), using the relationship:

$F_{\mathrm{m}}^{n}+G_{\mathrm{m}}^{n}=0$.

Subsequently, the equations for the temperatures at axial finite differences points and interior radial collocation points can be solved numerically. For the numbers of points, $N_{\mathrm{ax}}=15$ and $M_{\mathrm{rad}}=3$ were chosen as a rule.

\section{Interpolation}

The presented method yields $M \times N$ calculated temperatures at axial finite difference points and radial collocation points. The locations of these points are never the same as the axial and radial locations of temperature measurements in the experimental set-up. Therefore, for the fitting of temperatures, an interpolation method has to be employed.

A cubic spline interpolation (see Press et al. [24]) is applied in axial direction, at radial positions of the collocation points. This yields the calculated temperatures at the desired axial positions. Thus obtained temperatures at the radial collocation points are then used, together with Eq. (A12), to calculate the coefficients $a_{1} \ldots a_{\mathrm{M}}$ from Eq. (A11), using the collocation method backwards. With these values and Eq. (A11), it is then possible to calculate the temperatures at the desired radial positions.

$$
\left[\begin{array}{c}
a_{1}^{n} \\
\vdots \\
\vdots \\
\vdots \\
a_{\mathrm{M}}^{n}
\end{array}\right]=\left[\begin{array}{ccc}
\left\{\varrho_{1}^{2}-1-\frac{2}{\mathrm{Bi}_{\mathrm{t}}}\right\} & \cdots & \left\{\varrho_{1}^{2 M}-1-\frac{2 M}{\mathrm{Bi}_{\mathrm{t}}}\right\} \\
\vdots & \vdots \\
\vdots & \vdots \\
\vdots & \\
\left\{\varrho_{\mathrm{M}}^{2}-1-\frac{2}{\mathrm{Bi}_{\mathrm{t}}}\right\} & \cdots & \left\{\varrho_{\mathrm{M}}^{2 M}-1-\frac{2 M}{\mathrm{Bi}_{\mathrm{t}}}\right\}
\end{array}\right]^{-1} \times\left[\begin{array}{c}
\theta_{1}^{n} \\
\vdots \\
\vdots \\
\vdots \\
\vdots \\
\theta_{\mathrm{M}}^{n}
\end{array}\right]
$$

Substitution of Eq. (A 11) into Eq. (A 2), for all collocation points except the boundaries, yields the following set of equations:

$$
-\frac{1}{\mathrm{Bo}_{\mathrm{h}, \mathrm{r}}^{\Theta}} \times\left[\begin{array}{cccc}
\{4\} & \left\{16 \varrho_{1}^{2}\right\} & \ldots & \left\{4 M^{2} \varrho_{1}^{2 M-2}\right\} \\
\vdots & \vdots & & \vdots \\
\vdots & \vdots & & \vdots \\
\vdots & \vdots & & \vdots \\
\vdots & \vdots & & \vdots \\
\{4\} & \left\{16 \varrho_{\mathrm{M}}^{2}\right\} & \ldots & \left\{4 M^{2} \varrho_{\mathrm{M}}^{2 M-2}\right\}
\end{array}\right] \times\left[\begin{array}{c}
a_{1}^{n} \\
\vdots \\
\vdots \\
\vdots \\
\vdots \\
a_{\mathrm{M}}^{n}
\end{array}\right]=\left[\begin{array}{c}
G_{1}^{n} \\
\vdots \\
\vdots \\
\vdots \\
\vdots \\
G_{\mathrm{M}}^{n}
\end{array}\right]
$$




\section{Symbols used}

$$
\begin{array}{ll}
A, B, C & \\
A_{\mathrm{p}} & {\left[\mathrm{m}^{2}\right]} \\
\mathrm{Bi}_{\mathrm{t}} & {[-]} \\
& \\
\mathrm{Bo}_{\mathrm{h}, \mathrm{r}} & {[-]}
\end{array}
$$$$
\mathbf{B o}_{\mathrm{h}, \mathrm{r}}^{\ominus} \quad[-]
$$$$
C_{\mathrm{pg}} \quad\left[\mathrm{J} \mathrm{kg}^{-1} \mathrm{~K}^{-1}\right]
$$$$
D_{\mathrm{t}} \text { [m] }
$$$$
d_{\mathrm{p}}^{\mathrm{e}} \quad[\mathrm{m}]
$$

F

G

$\mathrm{G}$

L

$M$

$m$

$$
N
$$

$n$

$$
\mathrm{Pe}_{\mathrm{h}, \mathrm{a}} \quad[-]
$$$$
\mathrm{Pe}_{\mathrm{h}, \mathrm{a}}^{\Theta} \quad[-]
$$$$
\left[\mathrm{kg} \mathrm{m}^{-2} \mathrm{~s}^{-1}\right]
$$$$
\text { [m] }
$$$$
\text { [-] }
$$$$
\text { , a }[-]
$$

$\begin{array}{ll}\operatorname{Pr} & {[-]} \\ \mathrm{Re}_{\mathrm{p}}^{\mathrm{s}} & {[-]} \\ R_{\mathrm{t}} & {[\mathrm{m}]} \\ r & {[\mathrm{~m}]} \\ \mathrm{St} & {[-]}\end{array}$

constants in parabolic expressions external surface area of particle

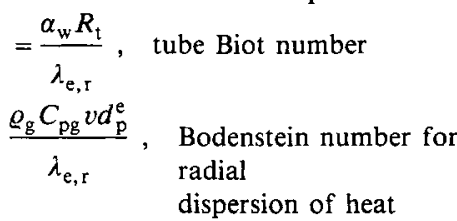

$\frac{\varrho_{\mathrm{g}} C_{\mathrm{pg}} v R_{\mathrm{t}}^{2}}{\lambda_{\mathrm{e}, \mathrm{r}} L}=\frac{\mathrm{Bo}_{\mathrm{h}, \mathrm{r}} N}{4 \Gamma}$, modified Bodenstein number for radial dispersion of heat

specific heat capacity of gas at constant pressure

tube diameter

$=\frac{6 V_{\mathrm{p}}}{A_{\mathrm{p}}}$, equivalent diameter of a sphere function

$\varrho_{\mathrm{g}} v$, gas mass flux

function

bed length

number of collocation points -2

index in radial direction

$=\frac{D_{\mathrm{t}}}{d_{\mathrm{p}}^{\mathrm{e}}}, \begin{aligned} & \text { number of particles on a } \\ & \text { diameter }\end{aligned}$

index in axial direction

$=\frac{\varrho_{\mathrm{g}} C_{\mathrm{pg}} v d_{\mathrm{p}}^{\mathrm{e}}}{\lambda_{\mathrm{e}, \mathrm{a}}}, \begin{aligned} & \text { Peclet number for axial } \\ & \text { dispersion of heat }\end{aligned}$

$=\frac{\varrho_{\mathrm{g}} C_{\mathrm{pg}} v L}{\lambda_{\mathrm{e}, \mathrm{a}}}, \begin{aligned} & \mathrm{Pe} \mathrm{e}_{\mathrm{h}, \mathrm{a}} N \Gamma, \text { modified axial } \\ & \text { Peclet number for heat }\end{aligned}$

$\frac{\eta_{\mathrm{g}} C_{\mathrm{pg}}}{\lambda_{\mathrm{g}}}, \quad$ Prandtl number

$=\frac{\varrho_{\mathrm{g}} v d_{\mathrm{p}}^{\mathrm{e}}}{}, \quad$ Reynolds number based on $\eta_{\mathrm{g}}$ superficial velocity

tube radius

radial coordinate

$$
=\frac{U_{\mathrm{ov}}}{\varrho_{\mathrm{g}} C_{\mathrm{pg}} v}, \begin{aligned}
& \text { Stanton number for } \\
& \begin{array}{l}
\text { overall heat transfer coef } \\
\text { ficient }
\end{array}
\end{aligned}
$$

$=\frac{U_{\mathrm{ov}} L}{\varrho_{\mathrm{g}} C_{\mathrm{pg}} v D_{\mathrm{t}}}=\mathrm{St} \Gamma, \begin{aligned} & \text { modified Stanton } \\ & \text { number }\end{aligned}$ temperature

temperature in the centre of packed bed at $\omega=0$

overall heat transfer coefficient, in onedimensional model particle volume superficial gas velocity axial coordinate wall heat transfer coefficient $\frac{\alpha_{\mathrm{w}} d_{\mathrm{p}}^{\mathrm{e}}}{\lambda_{\mathrm{g}}}, \begin{aligned} & \text { dimensionless wall heat } \\ & \text { transfer coefficient }\end{aligned}$ chi-square target function defined by Eq. (7) viscosity of gas
$\frac{L}{D_{\mathrm{t}}}$, aspect ratio

thermal conductivity of gas effective axial thermal conductivity

$\underline{\lambda_{e, a}}$, dimensionless effective axial $\lambda_{\mathrm{g}}$ thermal conductivity effective radial thermal conductivity

$\frac{\lambda_{e, r}}{\lambda}$, dimensionless effective radial $\lambda_{\mathrm{g}}$ thermal conductivity

$\frac{z}{L}$, dimensionless axial coordinate

$\frac{r}{R_{\mathrm{t}}}$, dimensionless radial coordinate

density of gas standard deviation

$\frac{\left(T_{\mathrm{z}, \mathrm{r}}-T_{\mathrm{cl}}\right)}{\left(T_{0}-T_{\mathrm{cl}}\right)}$, dimensionless temperature dimensionless mean-cup temperature defined by Eq. (13)

constant

defined in Eq. (2)

\section{Subscripts}

$\mathrm{cl}$

e

$\mathrm{g}$

out

$\mathrm{p}$

r

w

\section{Superscripts}

\section{e}

equivalent

superficial

\section{References}

[1] McHenry, K. W., Wilhelm, R.H., AIChE J. 3 (1957) pp. $83-91$.

[2] Young, L.C., Finlayson, B.A., Ind. Eng Chem. Fundam. 12 (1973) pp. $412-422$.

[3] Carberry, J. J., Wendel, M. M., AIChE J. 9 (1963) pp. 129 - 133.

[4] Marek, M., Hlavacek, V., Chem. Eng Sci. 21 (1966) pp. $493-500$.

[5] Hlavacek, V., Marek, M., Chem. Eng Sci. 21 (1966) pp. $501-514$.

[6] Mears, D.E., Ind. Eng Chem., Fundam. 15 (1976) pp. 20-23.

[7] Odendaal, W., Gobie, W., Carberry, J. J., Chem. Eng Commun. 58 (1987) pp. $37-62$.

[8] Gatica, J.E., Romagnoli, J.A., Errazu, A.F., Porras, J.A., Chem. Eng Commun. 78 (1989) pp. 73 - 96.

[9] Windes, L.C., Schwedock, M. J., Ray, W.H., Chem, Eng Commun. 78 (1989) pp. $1-43$.

[10] Wakao, N., Kaguei, S., Heat and mass transfer in packed beds, Gordon \& Breach, New York 1982.

[11] Gunn, D. J., Ahmad, M.M., Sabri, M.N., Chem. Eng Sci. 42 (1987) pp. $2163-2171$ 
[12] Borman, P. C., Borkink, J. G. H., Westerterp, K. R., Chem. Eng. Commun. 114 (1992) pp. $17-47$.

[13] Gunn, D. J., De Souza, J.F.C., Chem. Eng Sci. 29 (1974) pp. $1363-1371$.

[14] Gelbin, D., Radeke, K.H., Bosahl, B., Stein, W., Int. J. Heat Mass Transfer 19 (1976) pp. 987-994.

[15] Vortmeyer, D., Adam, W., Int. J. Heat Mass Transfer 27 (1984) pp. $1465-1472$.

[16] Li, C.H., Finlayson, B.A., Chem. Eng Sci. 32 (1977) pp. $1055-1066$.

[17] Wijngaarden, R.J., Thesis, Univ. Twente 1988.

[18] De Wasch, A.P., Froment, G.F., Chem. Eng Sci. 27 (1972) pp. $567-576$

[19] Dixon, A.G., Chem. Eng J (Loughborough, Engl.) 31 (1985) pp. $163-173$.

[20] Paterson, W. R., Carberry, J.J., Chem. Eng Sci. 38 (1983) pp $175-180$.

[21] Cresswell, D.L., Proc. NATO ASI 110 on Chem. React. Des. Tech. (ed. de Lasa, H. I.), Ontario/Canada, 1986, pp. 687-727.
[22] Ziolkowski, D., Legawiec, B., Chem. Eng Process. 21 (1987) pp. $65-76$.

[23] Parulekar, S. J., Ramkrishna, D., Chem. Eng Sci. 39 (1984) pp. $1571-1579$.

[24] Press, W.H., Flannery, B.P., Teukolsky, S.A., Vetterling, W.T., Numerical Recipes in Pascal: The Art of Scientific Computing, Cambridge Univ. Press, Cambridge 1989.

[25] Borkink, J.G.H., Thesis, Univ. Twente 1991.

[26] Borkink, J.G.H., Westerterp, K.R., AIChE J. 38 (1992) pp. $703-715$

[27] Borkink, J. G. H., Borman, P.C., Westerterp, K. R., Chem. Eng. Commun., to be published.

[28] Vortmeyer, D., Schaefer, R.J., Chem. Eng Sci. 29 (1974) pp. $485-491$.

[29] Dixon, A. G., Cresswell, D. L., AIChE J. 32 (1986) pp. 809-819.

[30] Kalthoff, O., Vortmeyer, D., Chem. Eng Sci. 35 (1980) pp. $1637-1643$

[31] Villadsen, J.V., Stewart, W.E., Chem. Eng Sci. 22 (1967) pp. $1483-1501$. 